\title{
"Assess The Impact of Eating Habits And Physical Activities on Weight Status Among School Age Children in Aselected Area of Aurangabad
}

\author{
Mr Deelip S Natekar, Dr Anuradha Mhaske². \\ ${ }^{1}$ Ph.D scholar MGM college of Nursing, N -6 CIDCO Aurangabad, 431003, Maharastra, India ${ }^{2}$ Principal, \\ MGM college of Nursing, $N$-6 CIDCO Aurangabad, 431003, Maharastra, India
}

\begin{abstract}
:
Background: In today's world one of the greatest problems for India is under nutrition among children. The country is still struggling with this problem. The Tibetan young children nutritional status of the entire population is poor and prevalence of malnutrition is higher. Eating habit as certain advantages but at the sometime the eating habit is also influencing the behavior of the children. As will as their physical and physiological health.
\end{abstract}

Aims and objectives: The study aimed at assessing impact of eating habits and physical activities on weight status among school age children, finding the correlation between physical activities, eating habits scores with weight status, and find out association between physical activities, eating habits and weight status scores scores with selected demographic variables.

Materials and methods: physical activity and eating habits are assessed by rating scale, weight statuus was determined by finding BMI 60 samples are selected by stratified random sampling.

Results: The study results shows that that majority of the children (76.6\%) has good eating habit, $100 \%$ had good physical activity, $65 \%$ are under weight. The correlation $(r=0.0281)$ value shows that mild correlation between weight status and physical activity of the school age children There was a significant association between eating habits with gender $\left(X^{2}=4, d f=1\right)$ and religion $\left(X^{2}=39.08, d f=1\right)$ physical activity with gender $\left(X^{2}=4.42, d f=1\right)$, weight status with gender $\left(X^{2}=5.44, d f=1\right)$

Conclusion: The study concludes that improve the good eating habits and physical activity for better weight status among school age children.

keywords: eating habits, physical activity, weight status, school age children

\section{Introduction}

Nutritional status during school age children is major determinant of nutritional and health status in adult life. In India health hazards associated with under nutrition and micronutrients deficiencies remain major health problems. The past three decades have witnessed the emergencies of over nutrition as a problem in school age children in developed countries.Important favorable health effects of physical activity for children's are extensively documented and well accepted by health professionals $(1,2,3,4)$. The benefits of physical activity in youth are less well documented. How-ever, reviewers have identified at least modest positive effects in the population or subsamples of youth on such health outcomes as aerobic fitness, blood lipids, blood pres-sure, body composition, glucose metabolism, skeletal health, and psychological health. Three groups have issued guidelines specifically for youth physical activity, and there is continuing debate over the amount and types of activity needed for health benefits. Recommendations tend to emphasize daily physical activity and encourage young people to accumulate 30 to $60 \mathrm{~min}$ ranging up to several hours per day. Because sustained moderate to vigorous physical activity has been associated with specific health benefits, this pattern of activity has also been recommended. Other recommendations have included activities to promote strength, flexibility bone health, and avoidance of extended periods of inactivity. Population surveys show that many young people are not meeting the guidelines.

\section{Need for study}

One of the greatest Problem for India is under nutrition. The country is still struggling with this problem. Nutritional deficiencies prior to school entry have the potential to impact upon cognitive outcome in school age children. In the united states which has the highest per capita soft drink consumption in the world. Globally including in India health hazards associated with under nutrition and micronutrients deficiencies remain major health problem. In the developed countries the consumption for higher caloric foods the increasing sedentary Lifestyle have been implicated as the major factor responsible for the rising obesity rates. Dietary behavior may also be affected by other social and cultural factors relating to food such as advertising and 
marketing and practices related to food production and consumption for instance whether food is consumed while watching televisions.Nutrition affects on children's physical cognitive and behavioral development. Television and computer games exposure affect children's sleep and deteriorate verbal cognitive performance which supports the hypothesis of the negative influences of media consumption on children's sleep, learning and memory. Most of the childhood obesity prevention efforts have focused on school age children and have had limited success.

\section{Objectives}

1. To assess the eating habits of school age children as measured by habit questionnaire

2. To determine the physical activities as expressed by school age children

3. To find out the weight status of school age children

4. To find the correlation between eating habits and weight status

5. To find the correlation between physical activities and weight status

6. To determine the association between eating habits with selected demographic variables

7. To find out the association between physical activities with selected demographic variables

8. To find out the association between weight status with selected demographic variables

\section{Hypothesis}

\section{Tested at 0.05 level of significance}

$\mathbf{H}_{1}$ : There is significant correlation between eating habits and weight status among school age children.

$\mathbf{H}_{2}$ : There is a significant correlation between eating habits and physical activities of school age children .

$\mathbf{H}_{3}$ : There is a significant correlation between weight status of the school age children.

$\mathbf{H}_{4}$ : there is a significant correlation association between eating habits with selected demographic variables.

$\mathbf{H}_{5}$ : there is a significant association between weight status with selected demographic variables.

$\mathbf{H}_{6}$ : there is a significant association between physical activities with selected demographic variables.

\section{Operational Definitions}

Eating habit: It is the habitual decisions an individual or culture makes when choosing what foods to eat.

Physical activity: It is defined as any bodily movement produced by skeletal muscles that requires energy expenditure.

Weight status: Refers to measurement of body fat in terms of BMI based on BMI categories i.e. Under weight= BMI of $<18.5$, Normal weight= BMI of 18.5-24.9, Over weight= BMI of 25-29.9, Obesity=BMI of 30 or greater

School age children: children in the age group of 8-12 years.

Material And Method :

\section{Sources of data:}

In this study the data will be collected from school age children in selected urban areas at Aurngabad District.

Research Design:

Descriptive correlation study design was used

Setting:

The study will be conducted at selected urban areas at Aurangabad District.

Population:

Population includes school age children

Method Of Data Collecton:

Sampling Technique:

Sample for the study will be selected by stratified sampling technique

Sample Size:

Sample size will comprise of 60 school age children.

Inclusion Criteria For Sampling:

1. The children willing to participate in the study.

2. The students who are available at the time of study

Exclusion Criteria For Sampling

1. Children are not willing to participate in the study.

\subsection{Sample characteristics}

\section{Indentations And Equations}

Majority of the students (58.5) Male and (41.5\%) Female children. Analysis Reveal that $29 \%$ of children had more than 15000 rupees, $28.33 \%$ of children had 10000-15000 Rupees, $13.33 \%$ children had 500010000 Rupees and 6\% children had less than 5000 Rupees income 
Fig no: 1. Cone diagram showing distribution of school age children according to gender $(\mathrm{N}=60)$

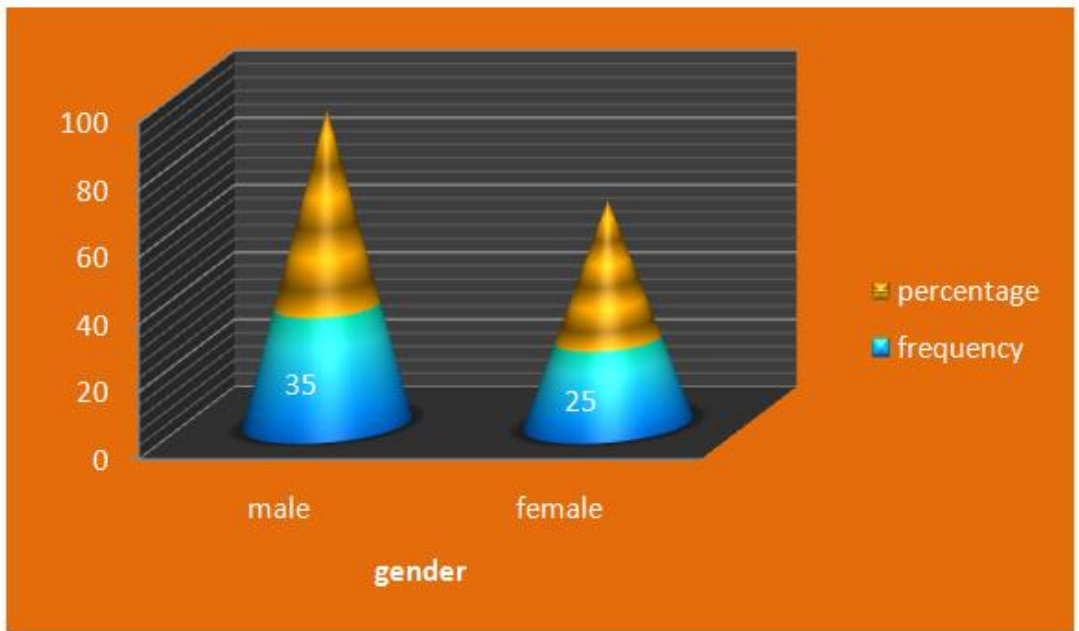

Fig no: 2. bar diagram showing distribution of school age children according to monthly income $(\mathrm{N}=60)$

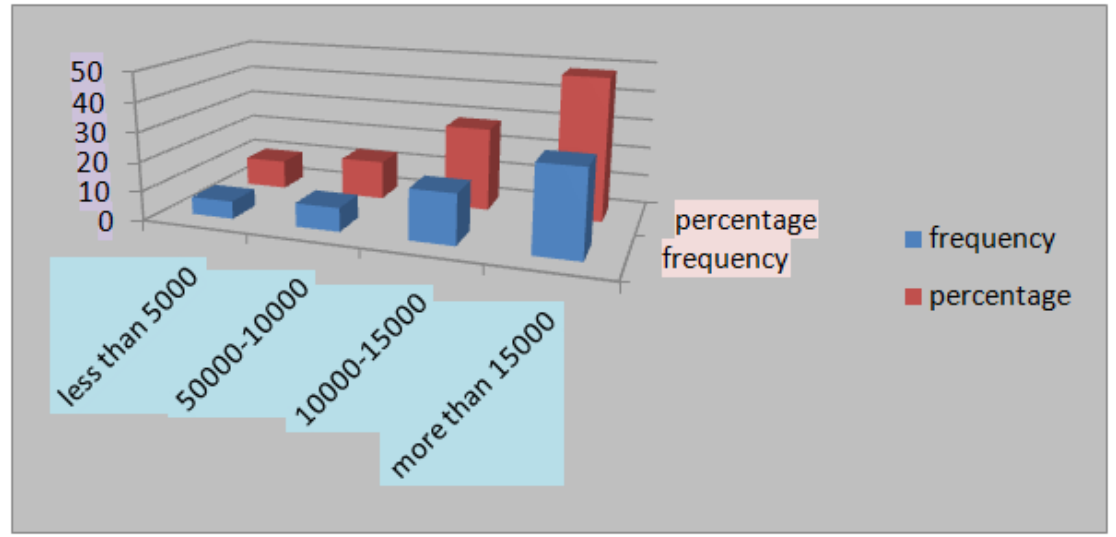

3.2 Eating habit: Assessment of the eating habit of school age children

\begin{tabular}{|l|l|l|l|}
\hline Grade & score & frequency & Percentage \\
\hline poor & $0-24$ & 5 & 8.3 \\
\hline good & $25-48$ & 43 & 76.6 \\
\hline excellent & $49-74$ & 9 & 15 \\
\hline total & & 60 & 100 \\
\hline
\end{tabular}

Table no 1:Data presented in table shows that majority of the children (76.6\%) has good eating habit and $(15 \%)$ of children had excellent eating habit.

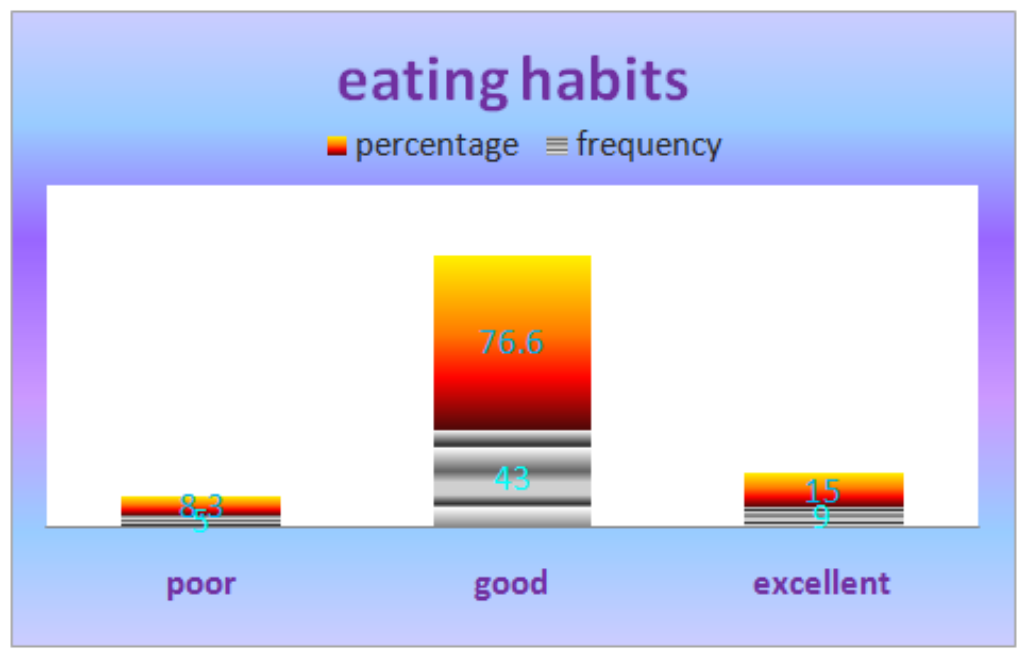

Fig 3: Column diagram showing the distribution of eating habit by school age children. 
3.3 physical activity of school age children.

\begin{tabular}{|l|l|l|l|}
\hline Scores & Item & Frequency & Percentage \\
\hline $14-28$ & Good & 60 & 100 \\
\hline $29-42$ & Excellent & 0 & 0 \\
\hline $0-14$ & Poor & 0 & 0 \\
\hline
\end{tabular}

Table 2: Data presented in table shows that majority of the children (100\%) having good physical activities.

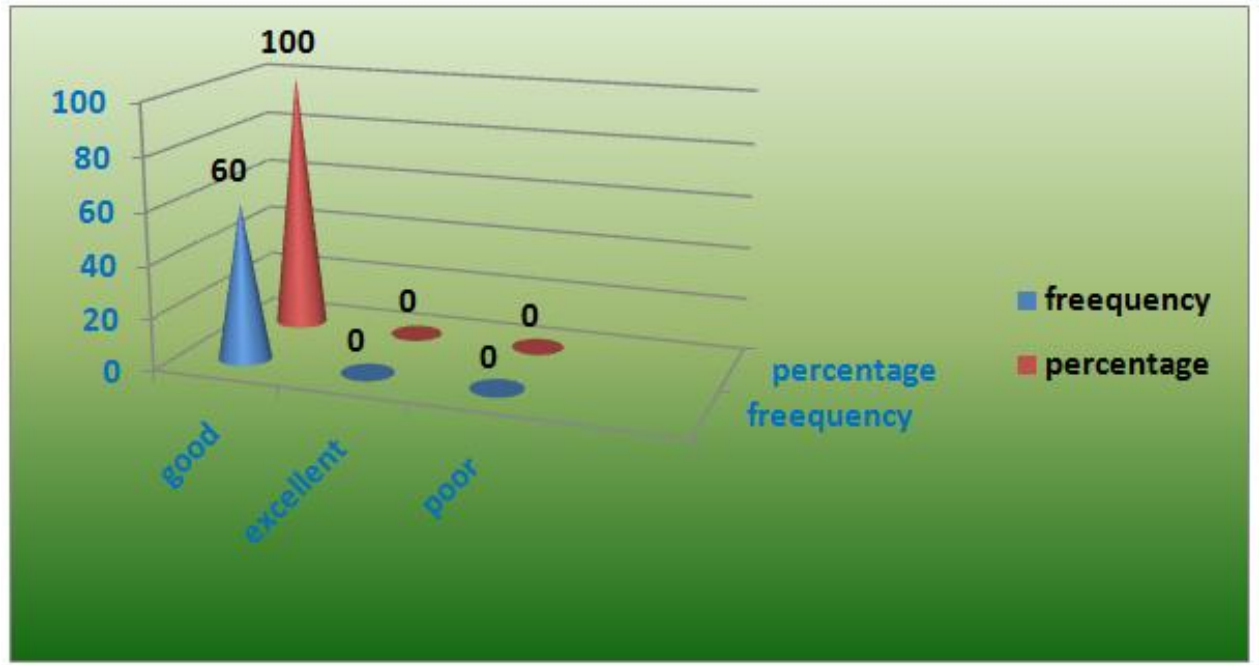

Fig 4: diagram showing the physical activities of school age children.

\subsection{Distribution of sample according to the weight status as measured by B.M.I}

\begin{tabular}{|l|l|l|l|}
\hline grades & score & frequency & percentage \\
\hline Under weight & $<18.5$ & 39 & 65 \\
\hline Normal weight & $19-24$ & 21 & 35 \\
\hline Over weight & $24-29.9$ & 0 & 0 \\
\hline obesity & $>30$ & 0 & 0 \\
\hline total & & 60 & 100 \\
\hline
\end{tabular}

Table 3: Data presented in table reveals that $65 \%$ of the children are Under weight ,35\% are having Normal weight, $0 \%$ of the children are having Over weight and $0 \%$ of children are having obesity.

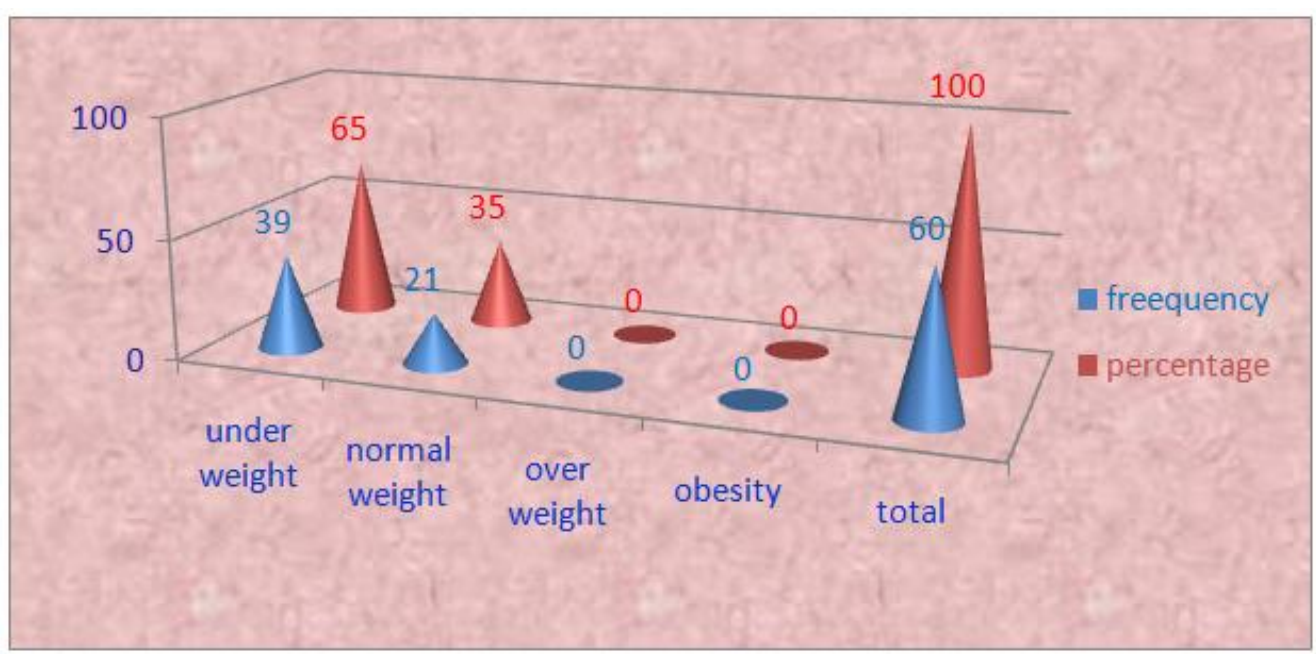

Fig 5 : Column diagram showing the distribution of body mass index(BMI) by school age children.

3.5 To find the correlation between eating habits and weight status $\mathbf{N}=\mathbf{6 0}$

\begin{tabular}{|l|l|l|}
\hline Item & R value & Significance \\
\hline Eating habits & 0.0384 & $\mathrm{~S}$ \\
\cline { 1 - 1 } Weight status & & \\
\hline
\end{tabular}

\section{S- Significance}

Table No : 4 Representing Correlation Between eating habits And weight status Score 
The above table shows there is a Mild correlation between eating habits and weight status score

3.6 To find the correlation between physical activities and weight status $\mathbf{N}=\mathbf{6 0}$

\begin{tabular}{|l|l|l|}
\hline Item & R value & Significance \\
\hline Physical activity & 0.0281 & $\mathrm{~S}$ \\
\cline { 1 - 1 } Weight status & & \\
\hline
\end{tabular}

\section{S- Significance}

Table No : 4 Representing Correlation Between physical activity And weight status Score

The above table shows there is a Mild correlation between physical activity and weight status score

3.7 Association between eating habits with selected demographic variables $\mathbf{N}=\mathbf{6 0}$

\begin{tabular}{|l|l|l|l|l|}
\hline SI NO & Demographic variables & \multicolumn{1}{|c|}{$\mathrm{X}^{2}$ value } & d .f & Significance \\
\hline 1 & Age & 3.44 & 1 & $\mathrm{~N} \mathrm{~S}$ \\
\hline 2 & Gender & 4.64 & 1 & $\mathrm{~S}$ \\
\hline 3 & Education & 3.44 & 1 & $\mathrm{~N} \mathrm{~S}$ \\
\hline 4 & Occupation of father & 1.58 & 1 & $\mathrm{~N} \mathrm{~S}$ \\
\hline 5 & Occupation of mother & 2.44 & 1 & $\mathrm{~N} \mathrm{~S}$ \\
\hline 6 & Income & 1.48 & 1 & $\mathrm{~N} \mathrm{~S}$ \\
\hline 7 & Religion & 39.08 & 1 & S \\
\hline 8 & Family & 0.08 & 1 & N S \\
\hline 9 & House & 1.2 & 1 & N S \\
\hline 10 & Diet & 2.4 & 1 & N S \\
\hline
\end{tabular}

\section{S - Significant NS - Not Significant}

Table No : 5 showing Association Between eating habits And selected Demographic Variables

The above Table shows that gender having association with eating habits.

3.7 Association between physical activity with selected demographic variables, $N=60$

\begin{tabular}{|l|l|l|l|l|}
\hline S no & Demographic variable & $\mathbf{X}^{2}$ values & D F & remarks \\
\hline 1 & Age & 3.44 & 1 & N S \\
\hline 2 & Gender & 4.42 & 1 & S \\
\hline 3 & Education & 3.44 & 1 & N S \\
\hline 4 & Occupation of father & 0.58 & 1 & N S \\
\hline 5 & Occupation of mother & 3.37 & 2 & N S \\
\hline 6 & Income & 3.88 & 2 & N S \\
\hline 7 & Religion & 1.36 & 1 & N S \\
\hline 8 & Family & 0.08 & 1 & N S \\
\hline 9 & House & 3.28 & 2 & N S \\
\hline 10 & Diet & 2.64 & 2 & N S \\
\hline
\end{tabular}

\section{S - Significant NS - Not Significant}

Table No : 6 Represents Association Between physical activity And Demographic Variable

The above table depicts gender having significant association with physical activity.

3.8 Association between weight status with selected demographic variables, $N=60$

\begin{tabular}{|l|l|l|l|l|}
\hline S no & Demographic variable & $\mathbf{X}^{2}$ values & D F & remarks \\
\hline 1 & Age & 3.44 & 1 & N S \\
\hline 2 & Gender & 5.44 & 1 & S \\
\hline 3 & Education & 3.44 & 1 & N S \\
\hline 4 & Occupation of father & 0.24 & 2 & N S \\
\hline 5 & Occupation of mother & 2.42 & 2 & N S \\
\hline 6 & Income & 3.38 & 2 & N S \\
\hline 7 & Religion & 1.36 & 1 & N S \\
\hline 8 & Family & 0.08 & 1 & N S \\
\hline 9 & House & 3.28 & 2 & N S \\
\hline 10 & Diet & 2.4 & 1 & N S \\
\hline
\end{tabular}

\section{S - Significant NS - Not Significant}

Table No : 6 Represents Association Between weight status And Demographic Variable

The above table depicts gender having significant association with weight status.

\section{Recommendations}

- A similar study can be done for a large samples to generalise the findings for a large population.

- A similar study can be done in different settings

- A experimental study can be done with control group

- A comparative study can be done in urban and rural area

- A study can be conducted to identify the problem due to impact of television on children 


\section{Conclusion}

The present study shows with small samples that many school age children are under weight, The study recommends that parents and school age children need some awareness programme to increase good eating habits, weight status.

\section{Acknowledgement}

I thank to all higher officials,parents involved in study, Principal, guide to extended their help and cooperation in completing the study.

\section{References}

[1]. Anurag Srivastava ,Syed E Mahmood, Payal M Srivastava, Ved P Shrotriya and Bhushan Kumar, Archives of public Health 2012,70:8 doi:10.1186/0778-7367-70-8, The electronic version of this article is the complete one and can be found online at: http://www.archpublichealth.com/content/70/1/8'

[2]. Pauline W Jansen 12,sabine J Roza23,Vincent WV Jaddoe145,Joreintje D Mackenbach2,Hein Raat6 Albert Holfman4,frank C Verhulst2 and Henning Tiemeier234,Correspondingauthor:Pauline W Jansen p.w.jansen@erasmusmc.nl online at http://www.ijbnpa.org/content/9/1/130

[3]. Apolinaras Zaborskis Dabone C ,Delisle H ,Receveur O,Glob HEALTH Promot .2013 Mar20(1):68-77.doi: .1177/ 1757975913476905, PMID:23563781[ Pubmed-indexed forMEDLINE]

[4]. Janssen I,Katzmarzyk PT,Boyce WF, Vereeken C, Mulvihill C, Roberts c,currie C, Pickett W; Health behavior in school aged children obesity working group,int j beh Nutr Phys Act.2011 November25;8: 130.doi: 10.1186/1479-5868-8-130, Dept of community health and Epidemology,Queens University,Kingstone,Ontario K7L 3N6,Canada. janseen@ post.queensu.ca,PMID:

[5]. Mushtaq MU, Gull s, Mushtaq k, Shahid U, shad MA ,Akram J , BMC public Health . 2011 May 17;11:328. Doi: 10.1186/14712458-11-328. 